\title{
Prostatic Perforation
}

National Cancer Institute

\section{Source}

National Cancer Institute. Prostatic Perforation. NCI Thesaurus. Code C78575.

An opening in the prostate gland due to traumatic or pathologic processes. 